median PFS of 1.8 months and overall survival of 7.3 months, compared with 1.3 months and 1.2 months PFS, and 5.5 months and 2.7 months overall survival, respectively, for $\mathrm{G} / \mathrm{G}$ and $\mathrm{A} / \mathrm{A}$ homozygotes.

The authors conclude that COX2 and EGFR polymorphisms might be useful independent predictors of outcome in patients with colorectal cancer treated with cetuximab.

Original article Lurje G et al. (2008) Polymorphisms in cyclooxygenase- 2 and epidermal growth factor receptor are associated with progression-free survival independent of $\mathrm{K}$-ras in metastatic colorectal cancer patients treated with single-agent cetuximab. Clin Cancer Res 14: 7884-7895

\section{Tumor-specific allogeneic $T$ cells treat solid tumors in mice}

Adoptive transfer of allogeneic $\mathrm{T}$ cells has successfully treated hematologic malignancies, but success against solid tumors has been limited, and the treatment is associated with development of graft-versus-host disease (GvHD). However, a study from the US National Cancer Institute supports the feasibility of this approach; Boni et al. used allogeneic T-cell transfer to treat solid tumors in mice. Rather than infusing an open repertoire of $T$ cells, the researchers transferred only tumor-specific T cells; an intensive, radioactive conditioning regimen aided the survival of donor cells.

$\mathrm{CD}^{+}$or $\mathrm{CD}^{+}{ }^{+} \mathrm{T}$ cells specific for melanoma antigens were transferred into melanomabearing mice. Mice that received 5 Gy of total body irradiation before cell transfer rejected the donor T cells; however, in mice that received 9 Gy of radiation combined with autologous bone marrow transplantation, donor $\mathrm{T}$ cells survived for several weeks and induced regression of large, vascularized tumors. Transfer of tumor-specific T cells alone, or in combination with small quantities of naive, open-repertoire $\mathrm{CD}^{+} \mathrm{T}$ cells, did not produce GvHD, only with cotransfer of large quantities of open-repertoire cells did GvHD occur.

The results suggest that antitumor treatment using allogeneic tumor-specific $T$ cells in combination with an intensive lymphodepletion regimen might be feasible. Although autologous cell treatment might be preferable, such cells can be difficult to obtain and the expansion process is time-consuming. Easily available allogeneic cells could deliver prompt treatment to patients. Use of restrictedrepertoire $\mathrm{T}$ cells might also reduce the risk of GvHD.

Original article Boni A et al. (2008) Adoptive transfer of allogeneic tumor-specific $\mathrm{T}$ cells mediates effective regression of large tumors across major histocompatibility barriers. Blood 112: 4746-4754

\section{Improved quality of life after treatment with amifostine for NSCLC}

Patient-reported outcomes provide important information regarding quality of life and symptom control. Radiation therapy for nonsmall-cell lung cancer (NSCLC) is known to be associated with pain and difficulty in swallowing. Assessment of these adverse effects by physicians can be different from the patient's own experience. Sarna and colleagues studied 138 patients from the Radiation Oncology Therapy Group trial 9801 to assess the changes in quality of life and symptoms in patients with stage II-III NSCLC treated with amifostine as induction therapy before radiation therapy. The authors hypothesized that patients who received amifostine would have improved quality of life and less pain than those without this treatment. Data were analyzed at baseline and 6 weeks after treatment with amifostine.

Patients treated with amifostine reported improvements in pain symptoms and less difficulty swallowing compared with those not treated with amifostine. These patients also reported less weight loss. Clinician-rated assessments, however, were not significantly different between treatment groups.

The authors conclude that, in addition to clinician-rated assessments, this study shows that patients' evaluations of symptoms such as pain and difficulty swallowing provide valuable information on treatment from their perspective. Amifostine reduced the pain and swallowing symptoms associated with radiation therapy for NSCLC.

Original article Sarna L et al. (2008) Clinically meaningful differences in patient-reported outcomes with amifostine in combination with chemoradiation for locally advanced nonsmall-cell lung cancer: an analysis of RTOG 9801. Int J Radiat Oncol Biol Phys 72: 1378-1384 